\title{
Een onderwijskwalificatie voor studenten
}

\author{
J. Spermon, R.L.A.W. Bleys, Th.E. Fick, Th.J. ten Cate
}

\section{Samenvatting}

Op basis van het inzicht dat in principe iedere arts een onderwijstaak heeft en hierin ook geschoold zou moeten worden, zit er in jaar 6 van de basisopleiding geneeskunde in Utrecht een verplichte onderwijsweek. Voor geïnteresseerde studenten bestaat de mogelijkheid om zich in jaar 6 verder in het medisch onderwijs te verdiepen en een Studenten Onderwijs Kwalificatie (StOK) te behalen. Daartoe volgen ze een onderwijsstage van zes weken of ze verdiepen zich onderwijskundig tijdens een studentassistentschap. De criteria voor het behalen van de StOK volgen de systematiek van de Basis- en Seniorkwalificaties van de Universiteit Utrecht en zijn opgesteld na bestudering van de literatuur en na gesprekken met begeleiders van onderwijsstages in het UMC Utrecht. Inmiddels zijn er in twee jaar tijd 51 StOK-certificaten uitgereikt bij een maximale bezetting van de beschikbare capaciteit. (Spermon J, Bleys RLAW, Fick ThE, Cate ThJ ten. Een onderwijskwalificatie voor studenten. Tijdschrift voor Medisch Onderwijs 2006;25(5):202-207.)

\section{Inleiding}

De professionalisering van docenten in de initiële en vervolgopleidingen krijgt steeds meer de aandacht die het verdient. De belangstelling voor docenttrainingen en onderwijskwalificaties neemt dan ook toe. Parallel daaraan is het idee ontstaan om volgens de systematiek van de onderwijskwalificaties voor docenten ook voor studenten een traject te ontwikkelen, waarmee een gecertificeerde onderwijskwalificatie kan worden behaald: een Studenten Onderwijs Kwalificatie (StOK). Dit artikel beschrijft de totstandkoming van de kwalificatie en de eisen die aan de studenten worden gesteld voor het behalen van die kwalificatie.

\section{Achtergrond}

Het zesde jaar van het Utrechtse geneeskundecurriculum (CRU'99) is als schakeljaar opgezet naar de systematiek van de algemene competenties voor een basisarts. De zeven competentiegebieden (medisch handelen, communicatie, samen- werking, kennis en wetenschap, maatschappelijk handelen, organisatie en professionaliteit) zijn afgeleid van de competentiegebieden zoals die door het Centraal College Medische Specialismen (CCMS) zijn vastgelegd voor de medische vervolgopleidingen. ${ }^{1-2}$ Het CCMS heeft daarbij het model van de Canadian Medical Education Directives for Specialists (CanMEDS) ${ }^{3}$ als uitgangspunt gebruikt.

De zeven competentiegebieden worden toegelicht met een algemene omschrijving in termen van feitelijk gedrag. Zo wordt bij het competentiegebied 'kennis en wetenschap' verwacht dat men in de dagelijkse praktijk zich onder andere bezighoudt met het bevorderen van deskundigheid van studenten ('medisch onderwijs') en andere betrokkenen bij de gezondheidszorg. Iedere arts hoort dus een bijdrage te leveren aan de medische kennisverwerving van anderen: van patiënten, collegae én ook van toekomstige collegae, de studenten. Op basis van deze inzichten heeft in principe iedere arts een 
onderwijstaak en zou hierin ook geschoold moeten worden. Dit komt tot uiting in de verplichte onderwijsweek tijdens het startblok van jaar 6 van de basisopleiding in Utrecht. Tijdens deze week maakt iedere student kennis met de medische onderwijskunde. Voor geïnteresseerde studenten bestaat vervolgens de mogelijkheid om zich tijdens een onderwijsstage van zes weken in jaar 6 verder in het medisch onderwijs te verdiepen en een onderwijskwalificatie te behalen. Tegelijk is de mogelijkheid gecreëerd om, in aanvulling op een studentassistentschap, deze verdieping ook vóór het zesde jaar op te doen. In beide gevallen kan dit leiden tot het behalen van een StOK, mits aan de criteria voor deze kwalificatie wordt voldaan.

\section{De Studenten Onderwijs Kwalificatie (StOK)}

Aangezien er voor docenten in het UMC Utrecht - volgens de personeelsregeling van de Universiteit Utrecht ${ }^{4}$ - trajecten zijn voor het behalen van een Basiskwalificatie Onderwijs (BKO) en een Seniorkwalificatie Onderwijs (SKO), ontstond het initiatief om ook voor studenten met interesse in medisch onderwijs een dergelijk kwalificatietraject te ontwikkelen. Met de begeleiders van studentassistenten bij de afdeling Anatomie en het Vaardigheidsonderwijs en met medewerkers van het Expertisecentrum voor Onderwijs en Opleidingen van het UMC Utrecht is nagegaan aan welke algemene eisen een student zou moeten voldoen om een Studenten Onderwijs Kwalificatie te kunnen behalen. Daarnaast is er in de literatuur gezocht naar criteria voor dergelijke kwalificaties. Er is veel gepubliceerd over 'peer teaching' in het medisch onderwijs en over projecten waarbij studenten of arts-assistenten als docent worden ingezet. ${ }^{5-11}$ Er werden echter geen artikelen gevonden waarin op basis van onderzoek de voor de studentdocent benodigde competenties zijn beschreven. Wel is er een vragenlijstonderzoek beschreven naar de rol van de arts-assistent als docent. Hier komt men tot een viertal kwaliteiten: doceren, communiceren, attitude en vaardigheden. ${ }^{12}$ Een arts-assistent zou onder andere leerproblemen bij studenten moeten kunnen herkennen en maatregelen kunnen nemen om deze te corrigeren.

\section{Criteria voor het behalen van de Studenten Onderwijs Kwalificatie}

Aan de hand van de onderwijs kwalificatietrajecten voor docenten, gesprekken met de begeleiders van studentassistenten en onderwijsdeskundigen is er een lijst met criteria voor een Studenten Onderwijs Kwalificatie tot stand gekomen.

De StOK-student dient over voldoende medische basiskennis te beschikken om als student-docent inzetbaar te zijn om andere studenten vakinhoudelijk adequaat te kunnen begeleiden. Hij moet op de hoogte zijn van het programma met de onderwijsdoelen van het curriculumonderdeel waarin het onderwijs wordt verzorgd. Er moet voldoende tijd aan de voorbereiding op het geven van onderwijs worden besteed en met een kritische blik naar de indeling ervan worden gekeken. De StOK-student moet in staat zijn feedback te geven op het programma en het onderwijs dat wordt verzorgd, maar daarbij ook alternatieven aan kunnen dragen. Hij kan inspelen op groepsprocessen, maar probeert het individu niet uit het oog te verliezen. Het gaat er om de studenten zo adequaat mogelijk te begeleiden in het leveren van leerprestaties. Enige kennis en ervaring op het gebied van de didactiek en bekendheid met hedendaagse medisch onderwijskundige principes is dus nodig. Ook is hij in staat fair en regelmatig leerprestaties te beoor- 
delen en kan hij relevante en bruikbare toetsvragen ontwikkelen. De StOK-student moet studenten ook kunnen coachen in hun leerprestaties en professioneel met hun problemen om kunnen gaan. Daarbij is hij steeds bereid om bij te leren en blijft hij reflectief; dit alles met een enthousiaste en gemotiveerde houding.

Uit bovenstaande profielschets kan een zevental kernkwaliteiten worden geformuleerd waaraan een StOK-student moet voldoen om een Studenten Onderwijs Kwalificatie te kunnen behalen:
- Vakinhoudelijk bekwaam.

- Didactisch georiënteerd.

- Adequaat onderwijs ontwerpen.

- Adequaat onderwijs uitvoeren.

- Leerprestaties toetsen.

- Communicatief en sociaal vaardig.

- Professionele attitude.

In tabel 1 staan de zeven kernkwaliteiten uitgewerkt, met de bijbehorende vereisten en de manier van toetsing. De student kan zo zelf nagaan in hoeverre hij heeft voldaan aan de gestelde eisen.

Tabel 1. Vereisten voor de Studenten Onderwijs Kwalificatie (StOK).

Voor de studenten-onderwijskwalificatie (geneeskunde) gelden de volgende algemene vereisten:

- Minimaal vier jaar (240 ECTS punten) (medisch) onderwijs voltooid.

- $\quad \mathrm{Ca} .280$ uren ervaring met verzorgen en geven van onderwijs.

- 30 uur hiervan in de vorm van zelfstandig verzorgd contactonderwijs, waarvan minimaal 12 uur nieuw contactonderwijs.

- $\quad$ Een afgeronde onderwijsportfolio.

\begin{tabular}{|c|c|c|}
\hline & $\begin{array}{l}\text { Specificering: De kandidaat } \\
\text { voor de StOK ... }\end{array}$ & Toetsing: Dit blijkt uit ... \\
\hline Vakinhoudelijk bekwaam & $\begin{array}{l}\text { beschikt over voldoende algemene } \\
\text { vakinhoudelijke kennis om onder- } \\
\text { wijs aan jongerejaars te kunnen } \\
\text { verzorgen; } \\
\text { - bezit specifieke kennis van het } \\
\text { terrein waarop onderwijs wordt } \\
\text { gegeven. }\end{array}$ & $\begin{array}{l}\text { - het met goed gevolg voltooid } \\
\text { hebben van vier jaar onderwijs } \\
\text { in de studierichting; } \\
\text { - een voldoende beoordeling van } \\
\text { deze vakinhoude-lijke kennis } \\
\text { door de superviserende } \\
\text { docent(en). }\end{array}$ \\
\hline Didactische oriëntatie & $\begin{array}{l}\text { - is op de hoogte van algemene } \\
\text { (medisch-)onder-wijskundige } \\
\text { uitgangspunten; } \\
\text { - is bekend met de uitgangspunten } \\
\text { van de onder-wijsfilosofie van het } \\
\text { curriculum; } \\
\text { - kan deze uitgangspunten, waar } \\
\text { nodig onder supervisie, toepassen; } \\
\text { - kan leerbehoefte bij studenten } \\
\text { herkennen en hiernaar handelen. }\end{array}$ & $\begin{array}{l}\text { - het met succes afgelegd hebben } \\
\text { van een toets medische onder- } \\
\text { wijskunde; } \\
\text { - het portfolio; } \\
\text { - het verslag van de super } \\
\text { viserende docent(en). } \\
\text { - het verslag van de super } \\
\text { viserende docent(en) en/of } \\
\text { studentenevaluatie(s). }\end{array}$ \\
\hline Adequaat onderwijs ontwerpen & $\begin{array}{l}\text { - kan tenminste één vorm van } \\
\text { contactonderwijs zinvol inrichten; } \\
\text { - kan zich adequaat voorbereiden } \\
\text { op het geven van onderwijs; }\end{array}$ & $\begin{array}{l}\text { - het verslag van de super } \\
\text { viserende docent(en) en } \\
\text { studentenevaluatie(s); } \\
\text { - het verslag van de super- } \\
\text { viserende docent(en); }\end{array}$ \\
\hline
\end{tabular}


- kan op het niveau van een studieonderdeel zin-vol vakinhoudelijk en medisch-onderwijskundig advies geven.
- de bruikbaarheid van de advisering volgens de super viserende docent(en) en/of uit de effectiviteit van het advies.

\begin{tabular}{|c|c|c|}
\hline Adequaat onderwijs uitvoeren & $\begin{array}{l}\text { - kan tenminste één vorm van } \\
\text { contactonderwijs adequaat } \\
\text { uitvoeren; } \\
\text { - kan de studenten op voldoende } \\
\text { wijze motiveren; } \\
\text { - kan de voorkennis van studenten } \\
\text { inschatten en daarop het onder- } \\
\text { wijs aanpassen; } \\
\text { - is in staat de student zo nodig te } \\
\text { begeleiden in het studeren. }\end{array}$ & $\begin{array}{l}\text { - het verslag van de super } \\
\text { viserende docent(en) en } \\
\text { studentenevaluatie(s); } \\
\text { - het verslag van de super } \\
\text { viserende docent(en) en } \\
\text { studentenevaluatie(s); } \\
\text { - het verslag van de super } \\
\text { viserende docent(en); } \\
\text { - het verslag van de super } \\
\text { viserende docent(en) en } \\
\text { studentenevaluatie(s). }\end{array}$ \\
\hline Leerprestaties toetsen & $\begin{array}{l}\text { - kan in het verzorgde onderwijs } \\
\text { studenten ade-quaat beoordelen } \\
\text { op grond van niet-schriftelijke } \\
\text { prestaties; } \\
\text { - is in staat bruikbare toetsvragen } \\
\text { te ontwikkelen; } \\
\text { - is in staat individueel en groeps- } \\
\text { gewijs gerichte feedback te geven } \\
\text { op prestaties en functioneren. }\end{array}$ & $\begin{array}{l}\text { - het verslag van de super } \\
\text { viserende docent(en) en uit } \\
\text { studentenevaluatie(s); } \\
\text { - minimaal } 10 \text { zelfgemaakte } \\
\text { toetsvragen van voldoende } \\
\text { kwaliteit; } \\
\text { - het verslag van de super } \\
\text { viserende docent(en), inter- } \\
\text { visieverslagen en/of studenten- } \\
\text { evaluatie(s). }\end{array}$ \\
\hline $\begin{array}{l}\text { Sociaal en communicatief } \\
\text { vaardig }\end{array}$ & $\begin{array}{l}\text { - kan op docentniveau met de } \\
\text { studenten en docenten commu- } \\
\text { niceren over het vak, onderwijs } \\
\text { en leren; } \\
\text { - heeft oog voor en reageert } \\
\text { adequaat op emotionele en } \\
\text { persoonlijke uitingen bij de } \\
\text { individuele student; } \\
\text { - kan op adequate wijze commu- } \\
\text { niceren over een onderwijskundig } \\
\text { of vakinhoudelijk onderwerp. }\end{array}$ & $\begin{array}{l}\text { - het verslag van de super } \\
\text { viserende docent(en) en } \\
\text { studentenevaluatie(s); } \\
\text { - het verslag van de super- } \\
\text { viserende docent(en) en } \\
\text { studentenevaluatie(s); } \\
\text { - een voldoende beoordeling } \\
\text { voor de schriftelijke of mon- } \\
\text { delinge verslaglegging over een } \\
\text { onderwijskundig onderwerp. }\end{array}$ \\
\hline Professionele attitude & $\begin{array}{l}\text { - staat open voor feedback over } \\
\text { de eigen onder-wijsprestaties en } \\
\text { kan hiermee het handelen zo- } \\
\text { nodig tussentijds bijstellen; } \\
\text { - is enthousiast en gemotiveerd; } \\
\text { - is zeker van zijn rol als docent en } \\
\text { kan omgaan met kritische vragen; } \\
\text { - is integer en kan omgaan met } \\
\text { vertrouwelijke informatie van en } \\
\text { over studenten. }\end{array}$ & $\begin{array}{l}\text { - het verslag van de super } \\
\text { viserende docent(en); } \\
\text { - het verslag van superviserende } \\
\text { docent(en) en studente- } \\
\text { valuatie(s); } \\
\text { - het verslag van superviserende } \\
\text { docent(en) en studente- } \\
\text { valuatie(s); } \\
\text { - het verslag van de super- } \\
\text { viserende docent(en). }\end{array}$ \\
\hline
\end{tabular}


In principe zijn er twee trajecten waarin de student een StOK kan behalen. Het eerste traject is de onderwijsstage in jaar 6. Tijdens deze stage moeten studenten minimaal 30 uur zelfstandig onderwijs geven aan jongerejaars studenten onder supervisie en moeten ze zich verdiepen in een medisch-onderwijskundig onderwerp via het lezen van literatuur en het schrijven van een paper. Daarnaast moeten ze toetsvragen ontwerpen, feedback geven ter verbetering van het onderwijs in het studieonderdeel waarbij ze zijn ingedeeld en moeten ze een toets afleggen over de artikelenserie $A B C$ of learning and teaching in medicine van het British Medical Journal.13 Het tweede traject is een onderwijsstage, gekoppeld aan een studentassistentschap. Deze stage kan al eerder in de opleiding starten. De StOK-kandidaat is een studentassistent bij het vaardigheidsonderwijs of de anatomie en gebruikt het keuzeonderwijs in jaar 4 en/of 5 om zich op vergelijkbare wijze in de medische onderwijskunde te verdiepen.

Voor beide trajecten geldt dat de geleverde inspanningen, in combinatie met de voor elke student verplichte onderwijstraining bij aanvang van jaar zes, na toetsing kan leiden tot het behalen van de StOK.

Tijdens het StOK-traject geven de studenten de onderwijscoördinatoren feedback op de inhoud van het onderwijs waar ze als studentdocent bij betrokken zijn. Ook geven ze op verzoek docenten feedback op door deze docenten verzorgd onderwijs (colleges, werkgroepen, e.d.).

\section{Conclusie en discussie}

Het zesde jaar van het Utrechtse geneeskundecurriculum is als schakeljaar opgezet naar de systematiek van de zeven competentiegebieden, waaraan de student moet voldoen met het oog op de medische vervolgopleidingen in Nederland. Omgaan met kennis en wetenschap, waartoe doceren behoort, maakt daar deel van uit. In zowel de initiële als de vervolgopleidingen is thans veel aandacht voor docentprofessionalisering. Om daar al in het schakeljaar van de basisopleiding in Utrecht aandacht aan te besteden, is de verplichte onderwijsweek tijdens het startblok opgezet. Het initiatief om daarnaast een onderwijskwalificatietraject te ontwikkelen voor studenten met meer belangstelling voor onderwijs, is een goed initiatief gebleken, gezien de belangstelling en de maximale bezetting van de stagecapaciteit. Als motivatie om een StOK te behalen wordt door de studenten onder meer aangegeven: interesse voor onderwijs, omdat je als arts onderwijsvaardigheden nodig hebt, om feedback te kunnen krijgen op gegeven onderwijs, om eigen geschiktheid voor het geven van onderwijs te bepalen, omdat het goed is voor je $\mathrm{CV}$ en omdat het leidt tot verdere verdieping van geneeskundige kennis.

Inmiddels zijn er vanaf augustus 2004, de start van het eerste schakeljaar (jaar 6) van het Utrechtse geneeskundecurriculum, tot augustus 200651 StOK-certificaten uitgereikt. Dat is ongeveer een achtste deel van het aantal studenten dat in die periode aan het schakeljaar is begonnen: een blijk van voldoende belangstelling voor docentprofessionalisering bij een groot aantal toekomstige collega's.

\section{Literatuur}

1. Bleker OP, Cate ThJ ten, Holdrinet RSG. De algemene competenties van de medisch specialist in de toekomst. Tijdschrift voor Medisch Onderwijs 2004;23:4-14.

2. Algemene competenties van de medisch specialist. Bijlage bij het kaderbesluit CCMS [homepage op internet]. Utrecht: KNMG; [geciteerd op 1309-2006]. Beschikbaar op: http://knmg.artsennet.nl/uri/?uri=AMGATE_6059_100_TICH_R1586 79960183152 
3. The Royal College of Physicians and Surgeons of Canada. The CanMEDS roles framework [homepage op internet] [geciteerd op 13-09-2006]. Beschikbaar op: http://rcpsc.medical.org/canmeds/ index.php.

4. De universitaire regeling WP-FLOW II. Functieprofielen, lLoopbanen en waardering voor wetenschappelijk medewerkers [monoloog op internet] [geciteerd op 13-09-2006]. Beschikbaar op: http://www.uu.nl/content/56_regeling_WP_FLOW _II_2006-1.pdf.

5. Borleffs JCC, Banga JD, Nieuwhof MGH, Erkelens DW. Les in onderwijzen. Nieuwe stage voor arts-assistenten. Med Contact 2003;58:1167-9.

6. Dunnington GL, DaRosa D. A prospective randomized trial of a residents-as-teachers training program. Acad Med 1998;73:696-700.

7. Ocel JJ, Palmer BA, Wittich CM, Carmichael SW, Pawlina W. Outcomes of the gross and developmental anatomy teaching assistant experience. Clin Anat 2003;16:526-30.

8. Centeno AM, Blanco M, Alejandra J, Campos S. A program for peer teachers in undergraduate medical education. Acad Med 2001;76(5):576.

9. Sobral DT. Cross-year peer tutoring experience in a medical school: conditions and outcomes for student tutors. Med Ecduc 2002;36:1064-70.

10. Gercama AJ, Tieleman D, Retel Helmrich A, Bastiaans JF. Resultaten van training en begeleiding van student-docenten in het klinisch lijnonderwijs. Tijdschrift voor medisch onderwijs 2001;20(3):114-23.
11. Solomon P, Crowe J. Perceptions of student peer tutors in a problem-based learning programme. Med Teach 2001;23(2):181-6.

12. Busari JO, Scherpbier AJJA, Vleuten van der CPM, Essed GE. Residents' perception of their role in teaching undergraduate students in the clinical setting. Med Teach 2000;22(4):348-53.

13. Cantillon P, Hutchinson L., Woods D, editors. $\mathrm{ABC}$ of learning and teaching in medicine. London: BMJ Publishing Group; 2003.

De auteurs:

Drs. J. Spermon, onderwijskundige en medisch student/semi-arts.

Dr. R.L.A.W. Bleys, anatoom, Divisie Hersenen.

Dhr. Th.E. Fick, chirurg n.p., coördinator docentprofessionalisering, Expertisecentrum voor Onderwijs en Opleidingen.

Prof. dr. Th. J. ten Cate, directeur Expertisecentrum voor Onderwijs en Opleidingen.

Alle auteurs zijn verbonden aan het UMC Utrecht.

Correspondentieadres:

Dhr. Th.E. Fick, chirurg n.p., Expertise Centrum voor Onderwijs en Opleidingen, UMC Utrecht, Hijmans van den Berghgebouw, Huispost 4.05, 3584 CG Utrecht; tel.:030-2503472, th.e.fick@umcutrecht.nl.

Belangenconflict: geen gemeld.

Financiële ondersteuning: geen gemeld.

\section{Summary}

The six-year undergraduate medical curriculum of University Medical Centre Utrecht contains an obligatory educational training period in Year 6. Students who want to attend additional educational training can take part in a six week education training period or gain experience in education as a student assistant. This programme of educational training opportunities is in line with the changes that are taking place in undergraduate medical education and postgraduate specialist training. Based on the literature and conversations with heads of various educational training courses, criteria have been established for a Students Teaching Qualification. (Spermon J, Bleys RLAW, Fick ThE, Ten Cate ThJ. A teacher qualification for medical students. Dutch Journal of Medical Education 2006;25(5):202-207.) 